\title{
FINANCIAL DISTRESS AND USE OF MENTAL HEALTH CARE: EVIDENCE FROM
}

\section{ANTIDEPRESSANT PRESCRIPTION CLAIMS}

\author{
HAIZHEN LIN ${ }^{*}$ \\ JONATHAN D. KETCHAM \\ JAMES N. ROSENQUIST \\ KOSALI I. SIMON
}

\begin{abstract}
Affiliations:
Lin, Department of Business Economics and Public Policy, Kelley School of Business, Indiana University

Ketcham, Department of Marketing, W.P. Carey School of Business, Arizona State University Rosenquist, Department of Psychiatry, Massachusetts General Hospital and Harvard Medical School

Simon, School of Public and Environmental Affairs (SPEA), Indiana University and NBER
\end{abstract}

\begin{abstract}
Using nationwide county-level longitudinal data, we show that recent declines in housing prices are associated with an increased utilization of antidepressant prescriptions among the near elderly. Our results persist in difference-in-difference models using either all nonantidepressant drugs or statins as controls.
\end{abstract}

Keywords: financial distress, housing crisis, mental health, prescription

Highlights: We study the impact of the housing crisis on the use of mental health treatment. We focus on the near elderly, among whom housing constitutes a substantial share of wealth holdings. For this population, prescription fills for antidepressants rise with falling county-level housing prices between 2006 and 2009. This finding is not due to an independent effect of the housing crisis on across-the-board use of medications.

\footnotetext{
${ }^{*}$ Corresponding author. 1309 E. $10^{\text {th }}$ St., Kelley School of Business, Indiana University, Bloomington, IN 47401. Phone: 1-812-855-9210. Email: hzlin@indiana.edu.
} 


\section{Introduction}

The housing market upheaval of the late 2000s hit many communities with record-setting declines in home values. According to the Freddie Mac Housing Price Index (HPI), from 2006 to 2009 housing prices experienced a 20-percent drop, the steepest witnessed in US history. We study the impact of the housing crisis on the use of mental health care by examining the use of antidepressant prescription drugs among the near elderly. One motivation for our focus on those age 55-64 is that recently released statistics show that suicide rates spiked sharply among this age group during this time period (Parker-Pope, 2013). This raises questions about the potential causes of a downturn in mental health among this population in particular. We investigate the potential role of housing because prior economic research has pointed out that this population has a high rate of home ownership and a high proportion of their savings held in the form of housing assets (Lusardi and Mitchell, 2007; Gustman, Steinmeier, and Tabatabai, 2011).

The expected effect of financial distress on the use of mental health treatment is ambiguous (Catalano, 2009). On the one hand, deteriorating economic conditions resulting from the housing crisis could increase the use of antidepressant medications due to elevated stress. On the other hand, economic stress could reduce the use of mental health treatment via reductions in access and ability to pay (Lusardi, Schneider, and Tufano, 2010), ${ }^{1}$ although the links between work, income and stress are complex (Ruhm, 2000).

Our empirical strategy is motivated by these potentially important but countervailing effects. Specifically, we first implement a baseline analysis that evaluates the link between changes in local housing prices and antidepressant prescription volume. We complement this analysis with a difference-in-difference (DD) strategy that controls for contemporaneous changes at the local level in a) all other drugs and b) medications known as "statins" used to treat high cholesterol.

This paper contributes to the existing literature on the impact of the housing crisis by providing clear empirical support for the association between aggregate movements in housing prices and the use of antidepressants. ${ }^{2}$ We find that the recent housing crisis is associated with increased use of antidepressant prescriptions. Our estimates indicate that the housing crisis can explain nearly a quarter of the increase in antidepressant use among the near elderly from the time with the highest HPI to the time with the lowest HPI during our study period. These results persist when we employ the DD models, albeit their magnitudes are attenuated. This supports the hypothesis that the prevalence of depression itself, which is among the diseases that are more sensitive to stress, is influenced by a decline in the HPI.

\section{Data and methods}

We utilize a large national dataset of prescription drug claims covering December 2004 through December 2009 from the Source Healthcare Analytics database (SHA, formerly Wolters Kluwer Health Source Lx database.). ${ }^{3}$ Prior research has demonstrated that prescription drug use

\footnotetext{
${ }^{1}$ A study by Case, Quigley and Shiller (2005) finds evidence that variations in housing market wealth, as compared to stock market wealth, have larger effects on household consumption.

${ }^{2}$ Other studies have looked at the impact of housing prices on birth rate (Dettling and Kearney, 2011; Lovenheim and Mumford, forthcoming) and college choice (Lovenheim and Reynolds, 2012). Another study by Currie and Tekin (2011) finds a strong link between foreclosures and hospitalization using hospital and emergency room visits data from four states.

${ }^{3}$ SHA acquires these data primarily from electronic switches that transmit claims between pharmacies and third parties such as pharmacy benefit managers. The data also include some "cash pay" prescriptions that do not generate any claims.
} 
is strongly and positively correlated with disease prevalence (e.g., Chini et al., 2011; Cossman et al., 2010). Our data include 505 million prescriptions filled by patients who were at least 55 years old by December 2004 and under 65 years old at the time they filled the prescription. These data cover 2,861 counties across all 50 states from approximately 32,000 pharmacies, including all of the major chains, other retail such as grocery stores or local pharmacies, mailorder, hospital and institutional pharmacies such as long-term care facilities. These data have been used in previous studies of prescription drug use (e.g., Ketcham and Simon (2008)).

The SHA database allows us to use the National Drug Classification code for each medication to identify a set of 35 drugs within the antidepressant therapeutic class. ${ }^{4}$ We aggregate the claim-level data for the near elderly by county-by-month to use in conjunction with data on local housing prices.

The housing price data are from the Freddie Mac HPI. This is compiled by analyzing transactions on single-family homes serving as collateral on loans that are purchased by Freddie Mac and Fannie Mae. This index, available at both the aggregated MSA and state levels, is considered a comprehensive and reliable measure of housing prices (e.g., Iacoviello, 2005). We construct the county-level HPI using the HPI index at the MSA level for counties located within MSAs ( $80 \%$ of the counties) and at the state level for non-MSA counties.

In addition, because the housing crisis overlaps with declining labor market conditions during the later months of our study period, we also account for the impact of the subsequent recession occurring throughout 2009 by controlling for contemporaneous changes in unemployment. These unemployment data are reported at the county-month level by the United States Bureau of Labor Statistics Local Area Unemployment Statistics program.

Our baseline model for the effect of housing prices on antidepressant use is specified as:

$$
y_{i s t m}=\beta_{0}+\beta_{1} H P I_{i s t m}+\beta_{2} U E R_{i s t m}+\alpha_{i}+\alpha_{m}+\omega_{s t}+\varepsilon_{i s t m}
$$

where $y_{\text {istm }}$ is the log of the number of prescriptions filled for drugs within the antidepressant therapeutic class by the near elderly in county $i$ state $s$ year $t$ and month $m .{ }^{5} H P I$ measures the housing price index and is our primary independent variable of interest. UER measures the county unemployment rate. The baseline model also includes county fixed effects $\alpha_{i}$ to control for time-invariant heterogeneity at the county level, month fixed effects $\alpha_{m}$ to account for seasonality, and state-year fixed effects $\omega_{s t}$ to control for all time-varying state-level factors that might affect the usage of antidepressant drugs such as the state-specific effects of the financial crisis or state-wide changes in Medicaid coverage and eligibility. Robust standard errors are estimated by clustering at the state level (Bertrand, Duflo, and Mullainathan, 2004).

Our second models employ the DD strategy working under the assumption that changes in non-antidepressant drugs will capture the effect of the housing crisis on drug use in general for reasons not linked directly to the effects of the housing crisis on mental health. We first use all non-antidepressant drugs, and then a specific class, statins, to serve as a contemporaneous control group. These models take the form:

$$
y_{\text {gistm }}=\gamma_{0}+G_{a n t i}+\gamma_{1} H P I_{i s t m}+\gamma_{2} G_{a n t i} * H P I_{i s t m}+\gamma_{3} U E R_{i s t m}+
$$

\footnotetext{
${ }^{4}$ These medications have FDA approval for the treatment of a variety of mood and anxiety-related conditions such as major depressive disorder and generalized anxiety disorder and are often used for the treatment of related symptoms such as insomnia. These medications account for well over $95 \%$ of all medications prescribed for major depression, as well as comorbid psychiatric conditions such as obsessive-compulsive disorder and generalized anxiety disorder. The names of these 35 drugs are listed in supplementary materials Table S-1.

${ }^{5}$ To deal with zero prescription in the data, we apply a log transformation to one plus the number of prescriptions.
} 


$$
\gamma_{4} G_{a n t i} * U E R_{i s t m}+\alpha_{i}+\alpha_{m}+\omega_{s t}+\varepsilon_{\text {gistm }}
$$

where $y_{\text {gistm }}$ is the log of prescription volume for the county-month for class $g$, which is either antidepressants or the control group, and $G_{a n t i}$ is the dummy for antidepressants. The primary parameter of interest is $\gamma_{2}$, which quantifies the relationship between housing prices and antidepressant prescription volume relative to the effect on the control group. The model also allows the effects of unemployment to differ between therapeutic classes. This DD approach has the additional advantage of eliminating any bias due to changes in the collection of the SHA data that may have been correlated with changes in local housing values.

\section{Results}

Figure 1 shows trends in the HPI and in antidepressant prescription volume nationwide from December 2004 to December 2009 for individuals aged 55 to 64. The values of both HPI and prescriptions are indexed to their December 2004 levels. The results show a remarkable pattern, with a correlation coefficient of -0.76. From 2005 through mid-2006 the data exhibit a persistent downward trend in antidepressant prescription volume as the HPI climbed through mid-2006. By mid-2007, antidepressant use began to climb while the HPI began to fall steadily, so that both return to their December 2004 levels at precisely the same time, October 2008. Beyond that, the HPI fell further through February 2009, reaching its nadir in the same month as antidepressant use reached its peak within the time period we study.

Table 1 shows the average county-by-month HPI, unemployment rate and antidepressant prescription volume separately for each year from 2004 to 2009. It also reports the volume of all non-antidepressant prescriptions and statins, again averaged by county and month.

The results from our baseline model reveal that HPI is negatively and significantly associated with antidepressant volume $\left(\beta_{1}=-0.375\right) .{ }^{6}$ Figure 2 provides a graphical illustration of the magnitude of this relationship. The $20 \%$ decline in housing prices experienced nationwide from its highest point in July 2006 to its lowest in February 2009 is associated with a $7.51 \%$ rise in antidepressant prescription volume (95\% CI 0.83\% - 14.18\%). These estimates indicate that the housing crisis explains nearly a quarter (22\%) of the $34 \%$ nationwide increase in antidepressant use among the near elderly from the highest to the lowest HPI during our study period. This estimated influence of HPI is net of any effects of unemployment and overall state-year factors, adding confidence that they represent true effects of the HPI rather than more general economic factors.

The results from the DD models also indicate a large, negative relationship between HPI and antidepressant use. Specifically, the key results of interest show that the negative association between HPI and antidepressant volume is significantly larger than the association between HPI and the prescription volume for all other drugs $\left(\gamma_{2}=-0.226\right)$ and for statins $\left(\gamma_{2}=-0.179\right)$. The magnitudes of these relative effects are illustrated in Figure 2, which shows that a $20 \%$ decrease in HPI yields a $4.52 \%$ (95\% CI $0.59 \%-6.55 \%$ ) increase in antidepressant use relative to all other drugs and a $3.57 \%$ (95\% CI $0.19 \%-8.85 \%)$ increase relative to statins.

\section{Discussion and conclusions}

In the recent history of the US, few events have caused more economic upheaval than the housing crisis. Our analysis demonstrates that a statistically significant link exists between the decline in housing prices and the rise in pharmacological treatments for depression, anxiety, and

\footnotetext{
${ }^{6}$ Detailed results from these models are reported in the supplementary materials Table S-2 for the basic model and Table S-3 for the DD models. .
} 
other co-morbid symptoms among the near elderly. Our results imply that the housing crisis was an important factor in the recent rise in antidepressant use among the near elderly, accounting for 22\% of the rise in prescription volume between July 2006 and February 2009 as the housing prices fell from their highest to their lowest levels nationwide.

Our estimates of the magnitude of the impact of housing prices are substantial. Yet given the under-treatment of depression nationwide (e.g., Gonzalez et al., 2010), the prevalence of depression may have grown even more than indicated by the increased use of antidepressants that we observe here. Evaluating the effects of the housing crisis on antidepressant use among other age groups would prove insightful, as would continued research of the effects of the economy on mental health more generally. Such results, in conjunction with those from this study, help point out that the true economic consequences of the recent housing crisis may go far beyond the costs typically captured by macroeconomic measures such as lost property value.

\section{Acknowledgements}

The authors are grateful to Rusty Jones and Jason Wreath at Source Healthcare Analytics, to Sean Nicholson at Cornell University, and to the staff of the Cornell Restricted Access Data Center. We thank Maurizio Fava, Roy Perlis, Jerrold Rosenbaum and Alex Tsai for their comments on this draft.

\section{References}

Bertrand M, Duflo E, Mullainathan S. 2004. How much should we trust differences-indifferences estimates? Quarterly Journal of Economics 119(1), 249-75.

Case KE, Shiller RJ, Quigley JM. 2005. Comparing wealth effects: The stock market versus the housing market. Advances in Macroeconomics, Berkeley Electronic Press 5(1), 235-1235.

Catalano, R. 2009. Health, medical care, and economic crisis. The New England Journal of Medicine 360 (8), 749-751.

Chini F, Pezzotti P, Orzella L, Borgia P, Guasticchi G. 2011. Can we use the pharmacy data to estimate the prevalence of chronic conditions? A comparison of multiple data sources. BMC Public Health 11, 688.

Cossman R, Cossman J, James W, et al. 2010. Correlating pharmaceutical data with a national health survey as a proxy for estimating rural population health. Population Health Metrics 8, 25.

Currie J, Tekin E. 2011. Is the foreclosure crisis making us sick? National Bureau of Economic Research Working Paper Series No. 17310.

Dettling LJ, Kearney MS. 2011. House prices and Brith rates: The impact of Real Estate Market on the decision to have a baby. National Bureau of Economic Research Working Paper Series No. 17485.

Gonzalez HM, Vega WA, Williams DR, Tarraf W, West BT, Neighbors HW. 2010. Depression care in the United States: Too little for too Few. Arch Gen Psychiatry 67, 37-46.

Gustman AL, Steinmeier TL, Tabatabai N. 2011. How did the recession of 2007-2009 affect the wealth and retirement of the near retirement age population in the Health and Retirement Study? National Bureau of Economic Research Working Paper Series No. 17547.

Iacoviello M. 2005. House prices, borrowing constraints, and monetary policy in the business cycle. The American Economic Review 95, 739-64.

Ketcham JD, Simon KI. 2008. Medicare Part D's effects on elderly patients' drug costs and utilization. American Journal of Managed Care 14, 14-22. 
Lusardi A, Mitchell OS. 2007. Baby Boomer retirement security: The roles of planning, financial literacy, and housing wealth. Journal of Monetary Economics 54(1), 205-224.

Lusardi A, Schneider D, Tufano P. 2010. The economic crisis and medical care usage. National Bureau of Economic Research Working Paper Series No. 15843.

Lovenheim MF, Mumford KJ. Do family wealth shocks affect fertility choices? Evidence from the housing market. Forthcoming, Review of Economics and Statistics.

Lovenheim MF, Reynolds CL. 2012. The effect of housing wealth on college choice: Evidence from the housing boom. National Bureau of Economic Research Working Paper Series No. 18075.

Parker-Pope T. 2013. Suicide rates in middle age soared in U.S. May 3, The New York Times, page A1.

Ruhm CJ. 2000. Are Recessions Good for Your Health? The Quarterly Journal of Economics 115(2), 617-650. 
Figure 1. National Housing Price Index (HPI) and Antidepressant Prescription Volume among the Near Elderly, December 2004 - December 2009

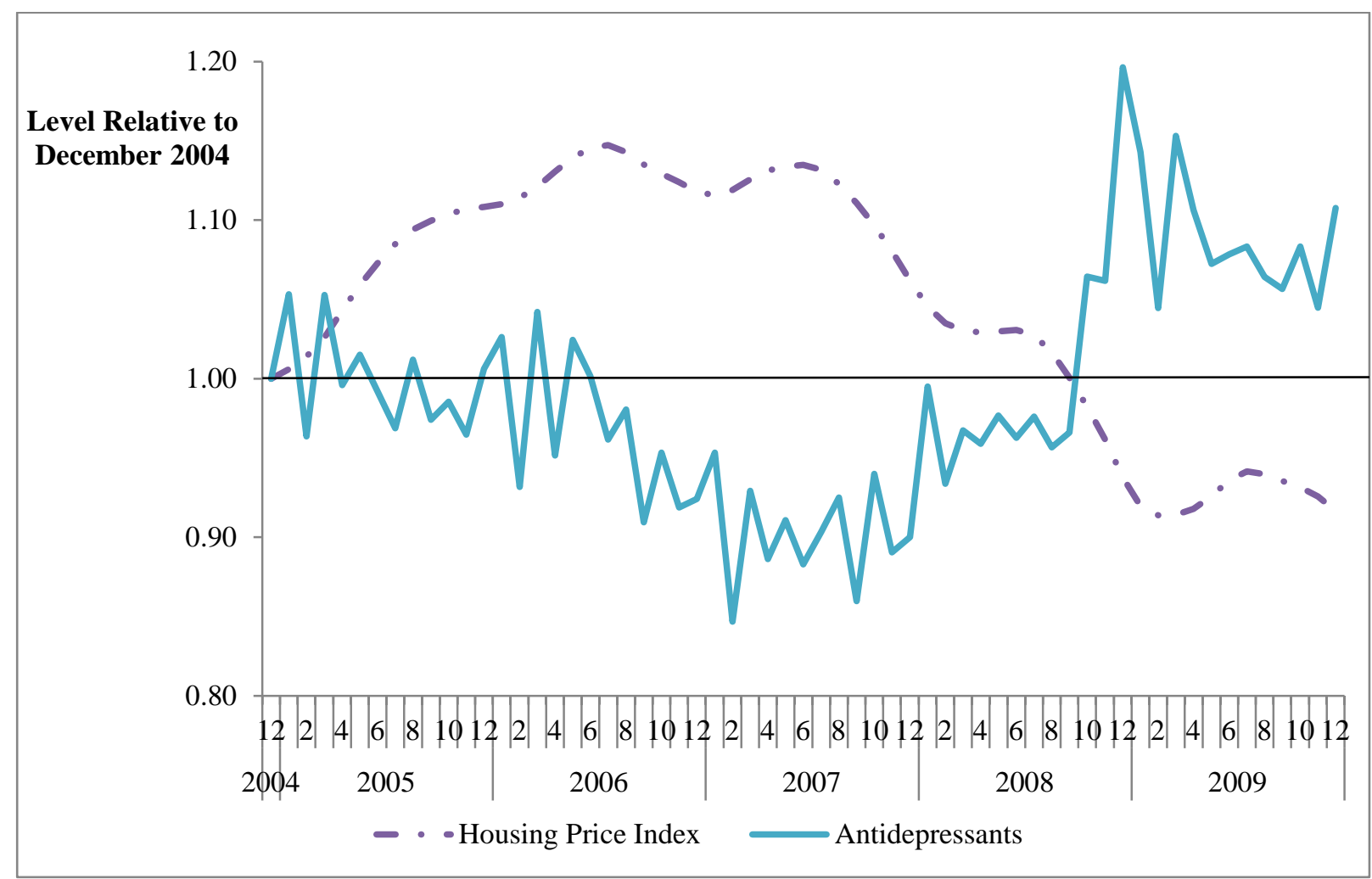


Figure 2. Estimated Relationship between County-by-month Housing Price Index (HPI) and Antidepressant Prescription Volume

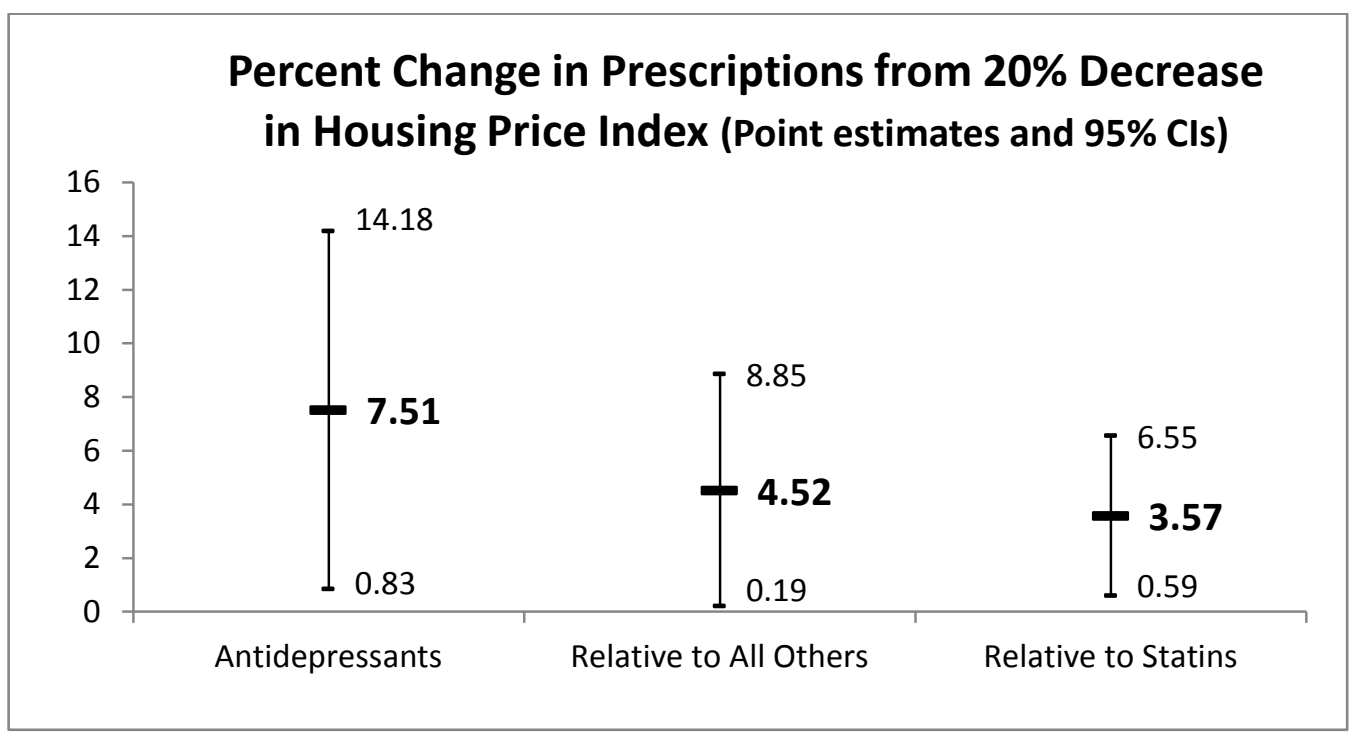


Table 1. County-by-month level variable means, by year

\begin{tabular}{lcccccc}
\hline & $\mathbf{2 0 0 4}$ & $\mathbf{2 0 0 5}$ & $\mathbf{2 0 0 6}$ & $\mathbf{2 0 0 7}$ & $\mathbf{2 0 0 8}$ & $\mathbf{2 0 0 9}$ \\
Freddie Mac Housing Price Index & & & & & & \\
$\quad$ Mean & 125.5 & 132.1 & 140.2 & 141.5 & 134.9 & 127.9 \\
$\quad$ Standard Deviation & 18.6 & 23.8 & 27.0 & 25.6 & 21.2 & 19.2 \\
$\quad$ & & & & & & \\
Unemployment Rate & 5.6 & 5.4 & 5.0 & 4.9 & 5.9 & 9.4 \\
$\quad$ Mean & 1.9 & 2.0 & 1.8 & 1.9 & 2.2 & 3.2 \\
$\quad$ Standard Deviation & & & & & & \\
Antidepressant prescriptions filled by near elderly & 192.9 & 192.9 & 187.8 & 182.4 & 200.0 & 218.0 \\
$\quad$ Mean & 545.6 & 570.5 & 521.0 & 442.0 & 587.2 & 651.4 \\
$\quad$ Standard Deviation & & & & & & \\
All non-antidepressant prescriptions filled by near elderly \\
$\quad$ Mean
\end{tabular}

Note: 2004 includes December only. 


\section{Supplementary Materials}

Table S-1. List of Drugs in the Antidepressant Therapeutic Class

\begin{tabular}{lll}
\hline Antidepressants & & \\
AMITRIPTYLINE HCL & AMOXAPINE & CLOMIPRAMINE HCL \\
DESIPRAMINE HCL & DOXEPIN HCL & IMIPRAMINE HCL \\
IMIPRAMINE PAMOATE & MAPROTILINE HCL & MIRTAZAPINE \\
NORTRIPTYLINE HCL & PROTRIPTYLINE HCL & TRIMIPRAMINE MALEATE \\
ISOCARBOXAZID & PHENELZINE SULFATE & SELEGILINE \\
TRANYLCYPROMINE SULFATE & BUPROPION HBR & BUPROPION HCL \\
NEFAZODONE HCL & TRAZODONE HCL & TRAZODONE HCL/DIET8 \\
CITALOPRAM HYDROBROMIDE & ESCITALOPRAM OXALATE & FLUOXETINE HCL \\
FLUVOXAMINE MALEATE & PAROXETINE HCL & PAROXETINE MESYLATE \\
SERTRALINE HCL & DESVENLAFAXINE SUCCINATE & DULOXETINE HCL \\
AMITRIP HCL/CL-DIAZEPOX HCL & AMITRIP HCL/CHLORDIAZEPOXIDE & VENLAFAXINE HCL \\
AMITRIPTYLINE HCL/PERPHENAZINE & PERPHENAZINE/AMITRIPTYLINE HCL & \\
StatinS & & \\
ATORVASTATIN CALCIUM & & \\
LOVASTATIN & & \\
SIMVASTATIN & & \\
\hline
\end{tabular}


Table S-2. Estimates from Baseline Model of Housing Prices on Antidepressant Prescription Volume

\begin{tabular}{cc}
\hline Dependent Variable: & $\begin{array}{c}\text { County-month } \\
\text { Antidepressant } \\
\text { Prescription Volume (log) }\end{array}$ \\
\hline
\end{tabular}

$\begin{array}{lc}\text { Freddie Mac Housing Price Index (log) } & -0.3754^{* *} \\ & (0.1662) \\ \text { Unemployment rate } & 0.0077^{*} \\ & (0.0043)\end{array}$

Model Includes:

Intercept Yes

County Fixed Effects $\quad$ Yes

Month Fixed Effects $\quad$ Yes

State-Year Fixed Effects Yes

Note: Robust standard errors, clustered at state level, are shown in brackets. *** $\mathrm{p}<0.01,{ }^{* *} \mathrm{p}<0.05,{ }^{*} \mathrm{p}<0.1 ; \mathrm{N}=153,658$. 
Table S-3. Estimates from Difference-in-Difference Models of Housing Prices on Antidepressant Prescription Volume Relative to Other Prescription Drug Classes

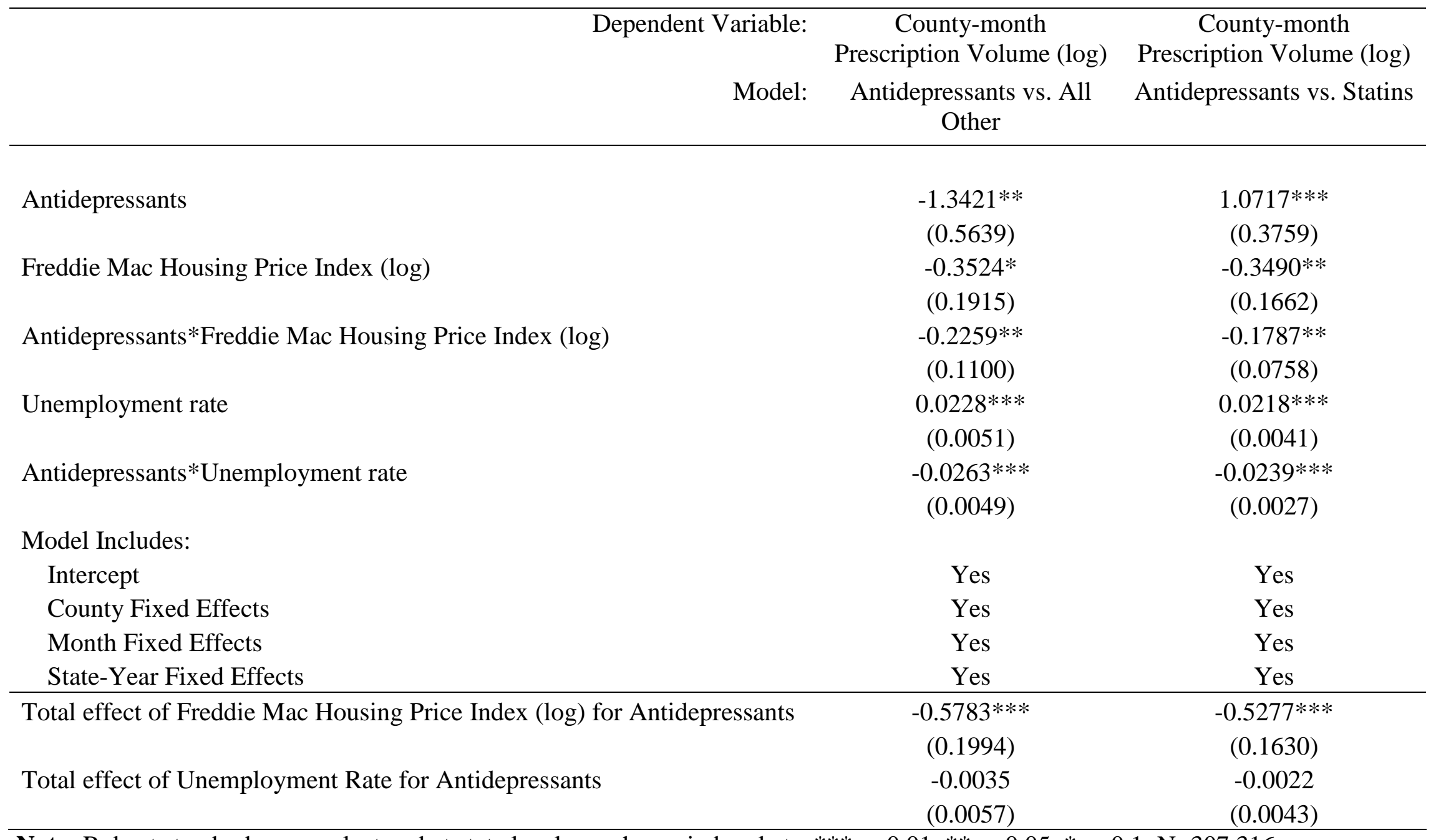

Note: Robust standard errors, clustered at state level, are shown in brackets. ${ }^{* * *} \mathrm{p}<0.01,{ }^{* *} \mathrm{p}<0.05,{ }^{*} \mathrm{p}<0.1 ; \mathrm{N}=307,316$. 